\title{
Latest Development on Membrane Fabrication for Natural Gas Purification: A Review
}

\author{
Dzeti Farhah Mohshim, Hilmi bin Mukhtar, Zakaria Man, and Rizwan Nasir \\ Chemical Engineering Department, Universiti Teknologi Petronas, Bandar Seri Iskandar, Perak Darul Ridzuan, \\ 31750 Tronoh, Malaysia
}

Correspondence should be addressed to Dzeti Farhah Mohshim; dzetifarhah@gmail.com

Received 4 September 2012; Accepted 1 November 2012

Academic Editor: Hyun Seog Roh

Copyright (c) 2013 Dzeti Farhah Mohshim et al. This is an open access article distributed under the Creative Commons Attribution License, which permits unrestricted use, distribution, and reproduction in any medium, provided the original work is properly cited.

In the last few decades, membrane technology has been a great attention for gas separation technology especially for natural gas sweetening. The intrinsic character of membranes makes them fit for process escalation, and this versatility could be the significant factor to induce membrane technology in most gas separation areas. Membranes were synthesized with various materials which depended on the applications. The fabrication of polymeric membrane was one of the fastest growing fields of membrane technology. However, polymeric membranes could not meet the separation performances required especially in high operating pressure due to deficiencies problem. The chemistry and structure of support materials like inorganic membranes were also one of the focus areas when inorganic membranes showed some positive results towards gas separation. However, the materials are somewhat lacking to meet the separation performance requirement. Mixed matrix membrane (MMM) which is comprising polymeric and inorganic membranes presents an interesting approach for enhancing the separation performance. Nevertheless, MMM is yet to be commercialized as the material combinations are still in the research stage. This paper highlights the potential promising areas of research in gas separation by taking into account the material selections and the addition of a third component for conventional MMM.

\section{Introduction}

Natural gas can be considered as the largest fuel source required after the oil and coal [1]. Nowadays, the consumption of natural gas is not only limited to the industry, but natural gas is also extensively consumed by the power generation and transportation sector [2]. These phenomena supported the idea of going towards sustainability and green technology as the natural gas is claimed to generate less-toxic gases like carbon dioxide $\left(\mathrm{CO}_{2}\right)$ and nitrogen oxides $\left(\mathrm{NO}_{x}\right)$ upon combustion as shown in Table 1 [3].

However, pure natural gas from the wellhead cannot directly be used as it contains undesirable impurities such as carbon dioxide $\left(\mathrm{CO}_{2}\right)$ and hydrogen sulphide $\left(\mathrm{H}_{2} \mathrm{~S}\right)$ [4]. All of these unwanted substances must be removed as these toxic gases could corrode the pipeline since $\mathrm{CO}_{2}$ is highly acidic in the presence of water. Furthermore, the existence of $\mathrm{CO}_{2}$ may waste the pipeline capacity and reduce the energy content of natural gas which eventually lowers the calorific value of natural gas [5].
Conventionally, natural gas treatment was predominated with some methods such as absorption, adsorption, and cryogenic distillation. But these methods require high treatment cost due to regeneration process, large equipments, and broad area for the big equipments [6]. With the advantages of lower capital cost, easy operation process, and high $\mathrm{CO}_{2}$ removal percentage, membrane technology offers the best treatment for natural gas [6]. Natural gas is expected to contain less than $2 \mathrm{vol} \%$ or less than $2 \mathrm{ppm}$ of $\mathrm{CO}_{2}$ after the natural gas treatment in order to meet the pipeline and commercial specification [7]. This specification is made to secure the lifetime of the pipeline and to avoid an excessive budget for pipeline replacement.

Membrane technology has received significant attention from various sectors especially industries and academics in their research as it gives the most relevant impact in reducing the environmental problem and costs. Membrane is defined as a thin layer, which separates two phases and restricts transport of various chemicals in a selective manner 
TABLE 1: Fossil fuel emission levels (pounds per billion Btu of energy input).

\begin{tabular}{lccc}
\hline $\begin{array}{l}\text { Fuel sources/pollutant } \\
\text { (pound/BTU) }\end{array}$ & Natural gas & Oil & Coal \\
\hline Carbon dioxide & 117,000 & 164,000 & 208,000 \\
Carbon monoxide & 40 & 33 & 208 \\
Nitrogen oxides & 92 & 448 & 457 \\
Sulphur dioxide & 1 & 1,122 & 2,591 \\
Particulates & 7 & 84 & 2,744 \\
Mercury & 0.000 & 0.007 & 0.016 \\
\hline
\end{tabular}

[8]. Membrane restricts the penetration of some molecules that have bigger kinetic diameter. The commercial value of membrane is determined by the membrane's transport properties which are permeability and selectivity. Major gap of the existing technologies is limited to low $\mathrm{CO}_{2}$ loading ( $<15 \mathrm{~mol} \%)$. Ideally, we required high permeability and high selectivity of membrane, but, however, most membranes exhibit high selectivity in low permeability and vice versa which make this is as a major tradeoff of membranes, and none of these technologies are yet to treat natural gas containing high $\mathrm{CO}_{2}(>80 \mathrm{~mol} \%)$ [9].

\section{Membrane Technology Development}

2.1. Early Membrane Development. Membrane technology has been started as early as in 1850 when Graham introduced the Graham's Law of Diffusion. Then, gas separation utilization in membrane technology has been commercialized in late 1900's. Permea PRISM membrane was the first commercialized gas separation membrane produced in 1980 [2]. Summary of early development of membranes is shown in Figure 1. This innovation has led to the further membrane gas separation development. A lot of studies done by the researchers for various gas separation mostly focus on the natural gas purification.

Development of membrane for $\mathrm{CO}_{2} / \mathrm{CH}_{4}$ separation has been started since early 1990's. Numbers of membranes were fabricated using different kind of materials in the early stage of this membrane gas separation. The desirable material selected must be well suited to the separation performance by which mean separation of gases works contrarily in different materials. Excellent gas membranes separation should have the characteristic of high separation performance with reasonable high permeability, high robustness, chemically, thermally, and mechanically good and rational production cost $[10,11]$. Two types of materials are practically used in gas separation: polymeric membrane and inorganic membrane and the comparison of both polymeric and inorganic membranes is showed in Table 2 .

Gas separation using polymeric membranes has taken its first commercial scale in late 1970's after the demonstration of rubbery membranes back in 1830's [33]. Literally, the permeability of gas in a specific gas mixture varies inversely with its separation factor. The tighter of molecular spacing it has, the higher the separation characteristic of the polymer, but, however, as the operating pressure increases, the permeability is decreasing due to experiencing lower diffusion coefficients [34]. Polymeric membranes that are commercially available for $\mathrm{CO}_{2} / \mathrm{CH}_{4}$ separation include polysulfone (PSU), polyetehrsulfone (PES), polyamide (PI) and many more. Generally, as the permeability of the gas increases, the permselectivity was attended to decrease in most cases of polymeric membranes [23].

Inorganic membrane like SAPO-34 could give higher separation performance compared to the polymeric membrane, but the separation performance is inversely proportional to the pressure loaded. This observation may create problem when we deal with high pressure natural gas well. The performance of both organic and inorganic membrane is summarized in Robeson's plot as in Figure 2 [35].

2.2. Conventional Mixed Matrix Membrane. A lot of researches have been done to satisfy the needs of gas separation requirement through both polymeric and inorganic membranes. The deficiencies of these membranes have driven the researchers to develop an alternative material for membrane which is more mechanically stable and economic viable, and most important is having high separation performance. The combination of organic and inorganic material which is known as mixed matrix membrane (MMM) was then proposed in idea to get a better membrane gas separation performance at reasonable price [36]. The fabrication of MMM was a promising technology as this composite material has improved its mechanical and electrical properties [37], and it combines the exceptional separation ability and pleasant stability of molecular sieves with better processability of organic membrane [38]. The MMM is characterized by dispersing the inorganic material into the continuous phase of polymeric material which can be almost any polymeric material such as polysulfone, polyimide, and polyethersulfones [39, 40].

Various membrane materials can be selected based on the process requirement. Selected materials can be "tailoredmade" in order to meet the specific separation purpose in a wide range of application [39]. There were many attempts of developing polymer-inorganic membrane that started few decades back then.

Based on Table 3, this was observed that the selection of materials is important, and it depends on the system requirement. Higher intrinsic diffusion selectivity characteristic of glassy polymer makes this material better than rubbery polymer [56]. Although MMM has proven an enhancement of selectivity, it was noticed that most MMMs were endured with poor adhesion between the organic matrix and inorganic particles [55]. Even MMM fabrication does have its disadvantages, but the research of MMM with different materials is worth to work on since it has proven its ability to have high separation performance.

\subsection{Recent Development of Membrane Gas Separation}

2.3.1. Ionic Liquid-Supported Membrane (ILSM). In recent years, many researches have been evaluated on the ionic 


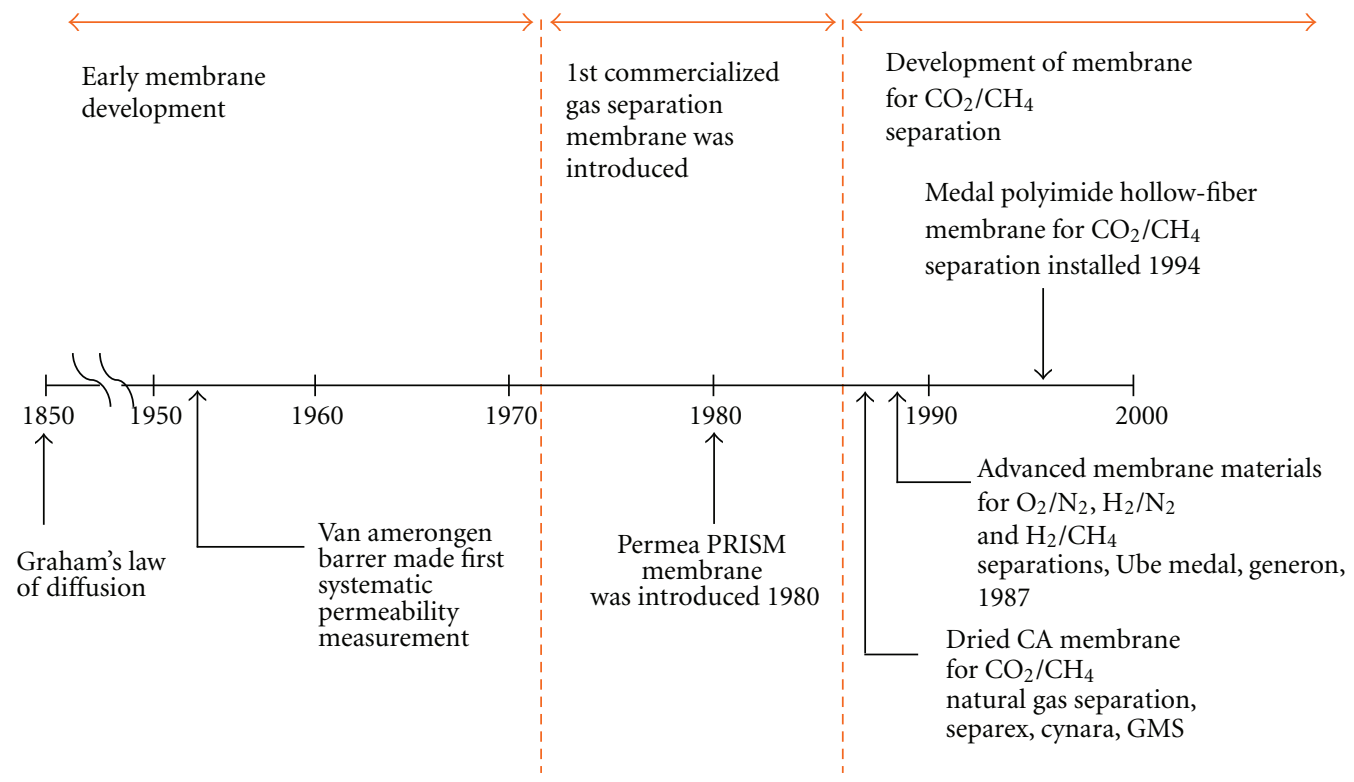

FIgURE 1: Membrane development timeline.

TABLE 2: Comparison between polymeric and inorganic membranes.

\begin{tabular}{|c|c|c|}
\hline & Polymeric membranes & Inorganic membranes \\
\hline Materials & $\begin{array}{l}\text { Present in either rubbery or glassy type which depends } \\
\text { on the operating temperature [12]. }\end{array}$ & $\begin{array}{l}\text { Made from inorganic-based material like glass, } \\
\text { aluminium, and metal [13]. }\end{array}$ \\
\hline Characteristics & $\begin{array}{l}\text { (i) Polymer is more rigid and hard in glassy state while } \\
\text { in rubbery state it is more soft and flexible } \\
\text { (ii) Glassy polymeric membranes exhibit higher glass } \\
\text { transition temperature compared to rubbery } \\
\text { membranes, and glassy types tend to have higher } \\
\mathrm{CO}_{2} / \mathrm{CH}_{4} \text { selectivity [14]. }\end{array}$ & $\begin{array}{l}\text { (i) Able to withstand with solvent and other chemicals } \\
\text { and also susceptible to microbial attack. } \\
\text { (ii) Comprise significantly higher permeability and } \\
\text { selectivity, but they are also more resistant towards } \\
\text { higher pressure and temperature, aggressive feeds, and } \\
\text { fouling effects [15]. }\end{array}$ \\
\hline Disadvantages & $\begin{array}{l}\text { (i) May have plasticization problem when handling } \\
\text { high } \mathrm{CO}_{2} \text {. } \\
\text { (ii) Presence of } \mathrm{CO}_{2} \text { may result in membrane } \\
\text { performance reduction at certain elevated pressure. } \\
\text { (iii) As the membranes expose to } \mathrm{CO}_{2} \text {, polymer } \\
\text { network in the membrane will swell, and segmental } \\
\text { mobility will also increase which consequently cause a } \\
\text { rise in permeability for all gas components [16]. } \\
\text { (iv) The components with low permeability } \\
\text { characteristic will experience more permeability } \\
\text { increment; thus, the selectivity of the membrane will } \\
\text { definitely decrease [17-19]. }\end{array}$ & $\begin{array}{l}\text { (i) Inherent brittleness characteristic. } \\
\text { (ii) Performed well under low pressure which does not } \\
\text { suit the natural gas well which required high pressure } \\
\text { for the exploration. } \\
\text { (iii) High production cost which seems not practical for } \\
\text { large industrial applications [20]. }\end{array}$ \\
\hline Examples & $\begin{array}{l}\text { Polyethylene (PE), poly(dimethylsiloxane) (PDMS), } \\
\text { polysulfone (PSU), polyethersulfone (PES), polyimide } \\
\text { (PI) [21], polycarbonate [22], polyimide [23], } \\
\text { polyethers [24], polypyrrolones [25, 26], polysulfones } \\
\text { [27], and polyethersulfones [28]. }\end{array}$ & $\begin{array}{l}\text { Aminoslicate membrane [29], carbon-silicalite } \\
\text { composite membrane [30], MFI membranes [31], and } \\
\text { microporous silica membranes [32]. }\end{array}$ \\
\hline
\end{tabular}

liquid supported membrane (ILSM) for gas separation membrane since ionic liquids are known materials that could dissolve $\mathrm{CO}_{2}$ and stable at high temperature ranges [57]. To be specific, ionic liquids are molten salt that are liquid at room temperature [58]. Furthermore, ionic liquids are of particular interest for membrane gas separation application as they are inflammable, negligible vapour pressure, and nonvolatile which make them also known as "green" solvents [5860]. Extensive researches have been carried out to develop room temperature ionic liquid (RTIL)-based solvents for $\mathrm{CO}_{2}$ separation with various types of ionic liquids such as pyridinium and imidazolium based. Among RTILs tested, imidazolium-based RTIL was chosen as the most feasible solvent for $\mathrm{CO}_{2}$ separation as they are commercially viable 
TABLE 3: Few researches of mixed matrix membranes.

\begin{tabular}{|c|c|c|c|c|}
\hline \multirow{2}{*}{ Year } & \multicolumn{2}{|c|}{ Mixed matrix membrane (MMM) } & \multirow[b]{2}{*}{ Observations } & \multirow{2}{*}{ Ref } \\
\hline & Organic & Inorganic & & \\
\hline 1973 & Silicon rubber & Molecular sieves & $\begin{array}{l}\text { Poor adhesion of organic and inorganic selected leads } \\
\text { to poor separation performance. } \\
\text { This poor interaction of both materials may result in } \\
\text { nonselective voids present at the interface which } \\
\text { consequently causes insufficient membrane } \\
\text { performance [ } 41-43] \text {. }\end{array}$ & [44] \\
\hline \multirow[t]{2}{*}{1992} & $\begin{array}{l}\text { Polydimethylsiloxane } \\
\text { (PDMS) }\end{array}$ & $\begin{array}{l}\text { Silicalite-1, 13X, KY, and } \\
\text { zeolite- } 5 \mathrm{~A}\end{array}$ & $\begin{array}{l}\text { Zeolite like silicalite- } 1,13 \mathrm{X} \text {, and } \mathrm{KY} \text { have enhanced the } \\
\text { separation performance of poorly selective rubbery } \\
\text { membrane for the carbon dioxide }\left(\mathrm{CO}_{2}\right) \text { and methane } \\
\left(\mathrm{CH}_{4}\right) \text { mixture. }\end{array}$ & [45] \\
\hline & $\begin{array}{l}\text { Propylene diene rubber } \\
\text { (EPDM) }\end{array}$ & & $\begin{array}{l}\text { Zeolite- } 5 \mathrm{~A} \text { showed no change in gas selectivity with } \\
\text { decrease permeability due to impermeable } \\
\text { characteristic towards } \mathrm{CO}_{2} \text {. }\end{array}$ & \\
\hline 2000 & Cellulose acetate (CA) & Silicalite, $\mathrm{NaX}$, and $\mathrm{AgX}$ & $\begin{array}{l}\text { Silicalite did in fact reverse the selectivity of CA } \\
\text { membrane from } \mathrm{H}_{2} \text { to } \mathrm{CO}_{2} \text { for } \mathrm{CO}_{2} / \mathrm{H}_{2} \text { separation. }\end{array}$ & [46] \\
\hline 2000 & Polyvinyl acetate & $4 \mathrm{~A}$ & $\begin{array}{l}\text { Formation of chemical bonds gave good adhesion, but } \\
\text { there is still nonselective "leakage" from the existence of } \\
\text { nanometric region. }\end{array}$ & [47] \\
\hline 2003 & Matrimid & Carbon molecular sieves & $\begin{array}{l}\text { Selectivity of } \mathrm{CO}_{2} / \mathrm{CH}_{4} \text { mixture has increased up to } \\
45 \% \text {. } \\
\text { Zeolites loading also affects both gas permeability and } \\
\text { gas mixture selectivity. There were also a number of } \\
\text { records where permeability increased with selectivity } \\
\text { decreased as the zeolites loading was increased }[48,49] \\
\text { and vice versa [42]. }\end{array}$ & {$[50]$} \\
\hline 2006 & Polyethersulfone (PES) & Zeolite 4A & Due to low mobility of the polymer chain in glassy & [53] \\
\hline 2001 & Polyimide $(\mathrm{PI})$ & Zeolite 13X & $\begin{array}{l}\text { polymer such as to prevent them to completely cover } \\
\text { the zeolites surface which resulted in void interface }\end{array}$ & {$[54]$} \\
\hline 2008 & Polycarbonate & Zeolite 4A & {$[51,52]$. } & [55] \\
\hline
\end{tabular}

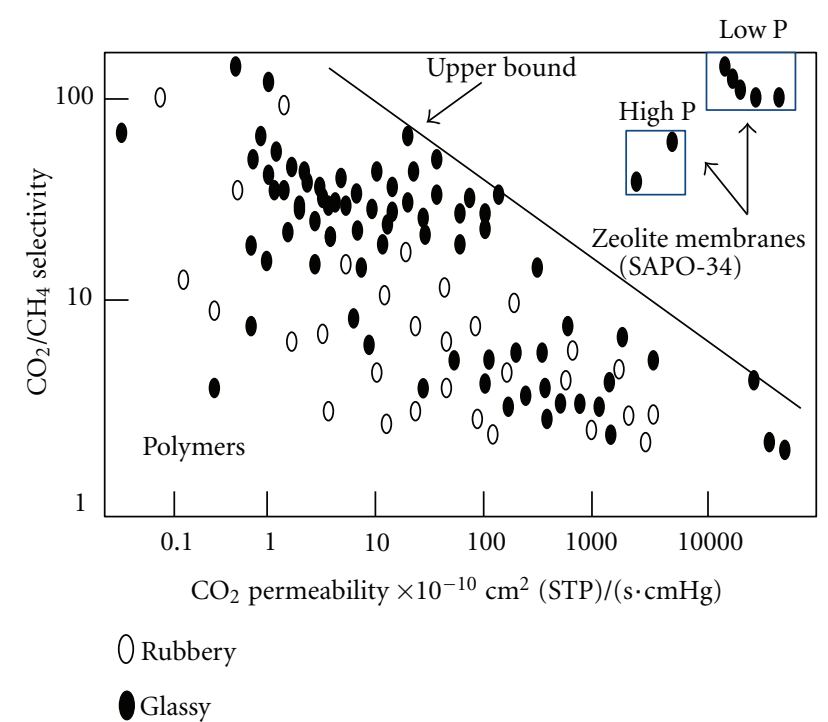

FIGURE 2: Zeolite (SAPO-34) membrane performance in Robeson's plot.

and easily tunable by tailoring the cation and anion to meet the system requirements [60].
ILSMs have been proven that they offered an increase in permeability that outperforms many neat polymer membranes. ILSMs synthesized from poly(vinylidene fluoride) (PVDF) and 1-butyl-3-methylimidazolium tetrafluororate $\left(\mathrm{BMImBF}_{4}\right)$ showed high permeation performance of $\mathrm{CO}_{2}$ and mechanically stable while operating at high pressure condition [63]. The consumption of RTILs showed an increment especially for 1-R-3-methylimidazolium (R-mim)based RTILs as this type is preferable due to its properties of less viscous compared to other RTILs. In addition, gases like $\mathrm{CO}_{2}$, nitrogen $\left(\mathrm{N}_{2}\right)$, and other hydrocarbons demonstrated high solubility in Rmim-based RTILs [64, 65]. Besides, the use of Rmim-based RTILs could calculate the latent permeability and selectivity of the mixture of given gases by using the molar volume of these RTILs [60]. RTIL can be functionalized and set up in according to the system requirement and application, and these researches could be good benchmark for designing the functionalized RTIL efficiently as showed in Table 4 .

2.3.2. Polymerized Room Temperature Ionic Liquid Membrane (Poly $(R T I L))$. Comparatively, RTIL especially imidazolium based can be also polymerized into a solid, dense, and thin film membrane due to their modular nature [66-68]. It was a successful breakthrough when the researcher found 
TABLE 4: Effects of ionic liquid functionalization.

\begin{tabular}{|c|c|}
\hline Functionalization & Effects \\
\hline $\begin{array}{l}\text { Nitrile and alkyne } \\
\text { group }\end{array}$ & $\begin{array}{l}\text { (i) Gas solubility and separation } \\
\text { performance have been tailored. } \\
\text { (ii) Functionalized RTIL solvents displayed a } \\
\text { decreasing in } \mathrm{CO}_{2}, \mathrm{~N}_{2} \text {, and } \mathrm{CH}_{4} \text { solubility, } \\
\text { but, however, the selectivity of } \mathrm{CO}_{2} / \mathrm{N}_{2} \text { and } \\
\mathrm{CO}_{2} / \mathrm{CH}_{4} \text { increased when compared to the } \\
\text { nonfunctionalized RTIL [61]. }\end{array}$ \\
\hline Temperature & $\begin{array}{l}\text { (i) As the temperature increases, the } \mathrm{CO}_{2} \\
\text { solubility is decreasing while the } \mathrm{CH}_{4} \\
\text { solubility remains unchanged. } \\
\text { (ii) The ideal solubility selectivity of mix } \\
\text { gases for } \mathrm{CO}_{2} / \mathrm{N}_{2}, \mathrm{CO}_{2} / \mathrm{CH}_{4} \text {, and } \\
\mathrm{CO}_{2} / \mathrm{H}_{2} \text { increased as the temperature } \\
\text { decreased [62]. }\end{array}$ \\
\hline
\end{tabular}

that polymer from ionic liquid monomer had higher $\mathrm{CO}_{2}$ absorption capacity with faster absorption and desorption rate compared to the neat RTIL [69]. Moreover, poly(RTIL) is also attributed with higher mechanical strength [66]. These characters have proven that polymerized ionic liquid (poly(RTIL)) is also a promising material for membrane gas separation. Polymerization of RTIL monomer by varying the $n$-alkyl length also showed a pleasant result when increase of permeability of given gases like $\mathrm{CO}_{2}, \mathrm{~N}_{2}$, and methane $\left(\mathrm{CH}_{4}\right)$ was observed as the $n$-alkyl group was lengthened [68]. Additionally, poly(RTIL) is also up to extend when it practically absorb about twice as much $\mathrm{CO}_{2}$ as their liquid analogue which makes it much better than molten RTIL [68]. Apparently, performance of poly(RTIL) also depends on the substituent attached to it. In a research done on the inclusion of a polar oligo(ethylene glycol) on the cation side of imidazolium-based RTIL, the separation selectivity has seemed to increase [70].

As discussed earlier, mixed matrix membrane is a known membrane that composed of a compatible organic-inorganic pair which demonstrated having good separation properties subject to no interfacial adhesion problem. The improvement of separation performance is expected in an MMM comprising poly(RTIL) (polymer matrix) and zeolite (inorganic). In a very recent work, the benefit of MMM has become an idea to the researcher in ionic liquid membrane field. Hudiono and his coworkers have introduced a three-component mixed matrix membrane by utilizing the poly(RTIL), RTIL, and zeolite [71]. Their research was also based on a positive finding by Bara and his coworkers when they found that the addition of RTIL in poly(RTIL) has increased the gas permeability. This is due to that more rapid gas diffusion occurred as the free volume of membrane increased when RTIL was added [72].

On the other hand, Hudiono has used the RTIL to increase the membrane permeability and also to act as an aid for better interaction between the poly(RTIL) and zeolite (SAPO-34). The result was promising as the permeability of given gases like $\mathrm{CO}_{2}, \mathrm{~N}_{2}$, and $\mathrm{CH}_{4}$ increased accordingly. However, the selectivity was slightly decrease as they claimed that the RTIL used which is emim[ $\left[\mathrm{Tf}_{2} \mathrm{~N}\right]$ was not selective towards $\mathrm{CO}_{2} / \mathrm{CH}_{4}$ separation [71]. Nonetheless, the result proved that the addition of RTIL could increase the polymerzeolite adhesion in MMM as RTIL also acts as the wetting agent for the zeolite.

Hudiono again repeated the same experiment fabricating a three-component mixed matrix membrane but by varying the composition of RTIL and zeolite added in order to determine the optimum condition for the membrane. The $\mathrm{CO}_{2}$ permeability seems to rise with the increasing amount of RTIL. The $\mathrm{CO}_{2} / \mathrm{CH}_{4}$ selectivity of the MMM also improved with the presence of SAPO-34 compared to neat poly(RTIL)RTIL membrane as long as there is sufficient amount of RTIL as the wetting agent. Besides, the team also conducted an investigation of the separation performance by using the vinyl-based poly(RTIL). The addition of RTIL is not essential as they are structurally similar [73].

In contrast, a ternary MMM has been fabricated by Oral and his coworkers by using different materials. The project study on the effect of different RTIL loadings which are emim $\left[\mathrm{Tf}_{2} \mathrm{~N}\right]$ and emim $\left[\mathrm{CF}_{3} \mathrm{SO}_{3}\right]$ towards MMM composed of polyimide-zeolite (SAPO-34). The addition of emim $\left[\mathrm{Tf}_{2} \mathrm{~N}\right]$ has performed as expected when the permeability of $\mathrm{CO}_{2}$ increased while the incorporation of emim $\left[\mathrm{CF}_{3} \mathrm{SO}_{3}\right]$ has increased the $\mathrm{CO}_{2} / \mathrm{CH}_{4}$ selectivity since emim $\left[\mathrm{CF}_{3} \mathrm{SO}_{3}\right]$ is selective towards $\mathrm{CO}_{2} / \mathrm{CH}_{4}$ [74].

\section{Conclusion}

The escalating research in the membrane fabrication for gas separation applications signifies that membranes technology is currently growing and becoming the major focus for industrial gas separation processes. Latest research area using mixed matrix membranes combines the flexibility and low capital cost with improving selectivity, permeability, chemical, thermal, and mechanical strength. Material selection and method of preparation are the most important part in fabricating a membrane. So the next research must be very careful in determining the materials for gas separation and methods applied in the fabrication stage. Even the synthesized MMMs were only tested in a small scale, the research of MMMs is worth to be further explored since MMMs have shown better separation performance compared to polymeric and inorganic membranes.

\section{References}

[1] Soregraph, Key World Energy Statistic, The International Energy Agency, 2010.

[2] Longterm Outlook to 2030, Natural Gas Demand and Supply, The European Union of The Natural Gas Industry, 2010.

[3] "Natural Gas and Environment-Emission from the Combustion of Natural Gas," copyright 2004-2010, http://www .naturalgas.org/environment/naturalgas.asp\#emission.

[4] A. Wan and A. Rusmidah, Natural Gas, Universiti Teknologi Malaysia, 2010.

[5] D. David and D. Kishore, Recent Development in $\mathrm{CO}_{2}$ Removal Membrane Technology, UOP, 1999. 
[6] M. I. Fauzi and A. Akkil, Meeting Technical Challenge in Developing High $\mathrm{CO}_{2}$ Gas Field Offshore, Petronas Carigali Sdn. Bhd., 2008.

[7] Fuels Providers, Natural Gas Specs Sheet, The National Petroleum Agency, 2002.

[8] Separation Process, Membrane Separation Process, Membrane Properties, 1998.

[9] Separation Process, Introduction to Membrane, Chapter 1, 1998.

[10] K. Scott, Membrane Separation Technology, Scientific \& Technical Information, Oxford, UK, 1990.

[11] H. Strathmann, "Membrane separation processes: current relevance and future opportunities," AIChE Journal, vol. 47, no. 5, pp. 1077-1087, 2001.

[12] S. Morooka and K. Kusakabe, "Microporous inorganic membranes for gas separation," MRS Bulletin, vol. 24, no. 3, pp. 25-29, 1999.

[13] A. F. Ismail and L. I. B. David, "A review on the latest development of carbon membranes for gas separation," Journal of Membrane Science, vol. 193, no. 1, pp. 1-18, 2001.

[14] W. A. W. Abdul Rahman, "Formation and characterization of mixed matrix composite materials for efficient energy gas separation," Project Report, Faculty of Chemical and Natural Resources Engineering, Universiti Teknologi Malaysia, 2006.

[15] J. A. Ritter and A. D. Ebner, "Carbon dioxide separation technology-R\&D needs for the chemical and petrochemical industries," Chemical Industry Vision 2020, 2007.

[16] T. Visser and M. Wessling, "When do sorption-induced relaxations in glassy polymers set in?" Macromolecules, vol. 40, no. 14, pp. 4992-5000, 2007.

[17] A. Bos, I. G. M. Pünt, M. Wessling, and H. Strathmann, " $\mathrm{CO}_{2}$ induced plasticization phenomena in glassy polymers," Journal of Membrane Science, vol. 155, no. 1, pp. 67-78, 1999.

[18] J. D. Wind, D. R. Paul, and W. J. Koros, "Natural gas permeation in polyimide membranes," Journal of Membrane Science, vol. 228, no. 2, pp. 227-236, 2004.

[19] J. D. Wind, S. M. Sirard, D. R. Paul, P. F. Green, K. P. Johnston, and W. J. Koros, "Relaxation dynamics of $\mathrm{CO}_{2}$ diffusion, sorption, and polymer swelling for plasticized polyimide membranes," Macromolecules, vol. 36, no. 17, pp. 6442-6448, 2003.

[20] A. J. Bird and D. L. Trimm, "Carbon molecular sieves used in gas separation membranes," Carbon, vol. 21, no. 3, pp. 177-180, 1983.

[21] T. H. Kim, W. J. Koros, G. R. Husk, and K. C. O’Brien, "Relationship between gas separation properties and chemical structure in a series of aromatic polyimides," Journal of Membrane Science, vol. 37, no. 1, pp. 45-62, 1988.

[22] J. S. McHattie, W. J. Koros, and D. R. Paul, "Effect of isopropylidene replacement on gas transport properties of polycarbonates," Journal of Polymer Science B, vol. 29, no. 6, pp. 731-746, 1991.

[23] C. L. Aitken, W. J. Koros, and D. R. Paul, "Gas transport properties of biphenol polysulfones," Macromolecules, vol. 25, no. 14, pp. 3651-3658, 1992.

[24] L. A. Pessan and W. J. Koros, "Isomer effects on transport properties of polyesters based on bisphenol-A," Journal of Polymer Science B, vol. 31, no. 9, pp. 1245-1252, 1993.

[25] D. R. B. Walker and W. J. Koros, "Transport characterization of a polypyrrolone for gas separations," Journal of Membrane Science, vol. 55, no. 1-2, pp. 99-117, 1991.
[26] X. Gao, Z. Tan, and F. Lu, "Gas permeation properties of some polypyrrolones," Journal of Membrane Science, vol. 88, no. 1, pp. 37-45, 1994.

[27] J. S. McHattie, W. J. Koros, and D. R. Paul, "Gas transport properties of polysulphones: 2 . Effect of bisphenol connector groups," Polymer, vol. 32, no. 14, pp. 2618-2625, 1991.

[28] Y. Liu, T. S. Chung, R. Wang, D. F. Li, and M. L. Chng, "Chemical cross-linking modification of polyimide/poly(ether sulfone) dual-layer hollow-fiber membranes for gas separation," Industrial and Engineering Chemistry Research, vol. 42, no. 6, pp. 1190-1195, 2003.

[29] G. Xomeritakis, C. Y. Tsai, and C. J. Brinker, "Microporous sol-gel derived aminosilicate membrane for enhanced carbon dioxide separation," Separation and Purification Technology, vol. 42, no. 3, pp. 249-257, 2005.

[30] L. Zhang, K. E. Gilbert, R. M. Baldwin, and J. Douglas Way, "Preparation and testing of carbon/silicalite-1 composite membranes," Chemical Engineering Communications, vol. 191, no. 5, pp. 665-681, 2005.

[31] M. P. Bernal, J. Coronas, M. Menéndez, and J. Santamaría, “On the effect of morphological features on the properties of MFI zeolite membranes," Microporous and Mesoporous Materials, vol. 60, no. 1-3, pp. 99-110, 2003.

[32] C. Y. Tsai, S. Y. Tam, Y. Lu, and C. J. Brinker, "Duallayer asymmetric microporous silica membranes," Journal of Membrane Science, vol. 169, no. 2, pp. 255-268, 2000.

[33] R. W. Baker, E. L. Cussler, W. Eykamp, W. J. Koros, R. L. Riley, and H. Strathmann, Membrane Separation Systems-Recent Developments and Future Directions, Noyes Data Corporation, 1991.

[34] D. E. W. Vaughan, "The synthesis and manufacture of zeolites," Chemical Engineering Progress, vol. 84, no. 2, pp. 25-31, 1988.

[35] M. A. Carreon, Novel Membranes for Efficient $\mathrm{CO}_{2}$ Separation, University of Lousville, 2011.

[36] S. Kulprathipanja, R. W. Neuzil, and N. N. Li, "Separation of fluids by means of mixed matrix membranes in gas permeation," US Patent 4,740,219, 1988.

[37] T. M. Gür, "Permselectivity of zeolite filled polysulfone gas separation membranes," Journal of Membrane Science, vol. 93, no. 3, pp. 283-289, 1994.

[38] L. Yi, Development of Mixed Matrix Membrane for Gas Separation Application, Tsinghua University, 2006.

[39] C. M. Zimmerman, A. Singh, and W. J. Koros, "Tailoring mixed matrix composite membranes for gas separations," Journal of Membrane Science, vol. 137, no. 1-2, pp. 145-154, 1997.

[40] R. Mahajan, C. Zimmerman, and W. Koros, Fundamental, Practical Aspects of Mixed Matrix Gas Separation Membranes, ACS Symposium Series, 1999.

[41] V. Bhardwaj, A. MacIntosh, I. D. Sharpe, S. A. Gordeyev, and S. J. Shilton, "Polysulfone hollow fiber gas separation membranes filled with submicron particles," Annals of the New York Academy of Sciences, vol. 984, pp. 318-328, 2003.

[42] R. Mahajan, R. Burns, M. Schaeffer, and W. J. Koros, "Challenges in forming successful mixed matrix membranes with rigid polymeric materials," Journal of Applied Polymer Science, vol. 86, no. 4, pp. 881-890, 2002.

[43] M. G. Süer, N. Baç, and L. Yilmaz, "Gas permeation characteristics of polymer-zeolite mixed matrix membranes," Journal of Membrane Science, vol. 91, no. 1-2, pp. 77-86, 1994.

[44] D. R. Paul and D. R. Kemp, "The diffusion time lag in polymer membrane containing adsorptive fillers," Journal of Polymer Science C, no. 41, pp. 79-93, 1973. 
[45] J. M. Duval, B. Folkers, M. H. V. Mulder, G. Desgrandchampsb, and C. A. Smolders, "Adsorbent filled membranes for gas separation. Part 1. Improvement of the gas separation properties of polymeric membranes by incorporation of microporous adsorbents," Journal of Membrane Science, vol. 80, no. 1, pp. 189-198, 1992.

[46] S. Kulprathipanja, "Review of recent progress in mixed matrix membranes," Membrane Technology, vol. 105, pp. 6-8, 2000.

[47] R. Mahajan and W. J. Koros, "Factors controlling successful formation of mixed-matrix gas separation materials," Industrial and Engineering Chemistry Research, vol. 39, no. 8, pp. 2692-2696, 2000.

[48] J. M. Duval, Adsorbent filled polymeric membranes [Ph.D. thesis], The University of Twente, 1995.

[49] Z. Huang, J. F. Su, X. Q. Su, Y. H. Guo, L. J. Teng, and C. M. Yang, "Preparation and permeation characterization of $\beta$ zeolite-incorporated composite membranes," Journal of Applied Polymer Science, vol. 112, no. 1, pp. 9-18, 2009.

[50] D. Q. Vu, W. J. Koros, and S. J. Miller, "Mixed matrix membranes using carbon molecular sieves: I. Preparation and experimental results," Journal of Membrane Science, vol. 211, no. 2, pp. 311-334, 2003.

[51] M. D. Jia, K. V. Peinemann, and R. D. Behling, "Preparation and characterization of thin-film zeolite-PDMS composite membranes," Journal of Membrane Science, vol. 73, no. 2-3, pp. 119-128, 1992.

[52] T. W. Pechar, S. Kim, B. Vaughan et al., "Preparation and characterization of a poly(imide siloxane) and zeolite L mixed matrix membrane," Journal of Membrane Science, vol. 277, no. 1-2, pp. 210-218, 2006.

[53] Z. Huang, Y. Li, R. Wen, M. M. Teoh, and S. Kulprathipanja, "Enhanced gas separation properties by using nanostructured PES-zeolite 4A mixed matrix membranes," Journal of Applied Polymer Science, vol. 101, no. 6, pp. 3800-3805, 2006.

[54] H. H. Yong, H. C. Park, Y. S. Kang, J. Won, and W. N. Kim, "Zeolite-filled polyimide membrane containing 2,4,6triaminopyrimidine," Journal of Membrane Science, vol. 188, no. 2, pp. 151-163, 2001.

[55] D. Sen, Polycarbonate based zeolite 4A filled mixed matrix membranes: preparation, characterization and gas separation performances [Ph.D. thesis], Middle East Technical University, 2008.

[56] D. R. Paul and D. R. Kemp, "Diffusion time lag in polymer membranes containing adsorptive fillers," Journal of Polymer Science C, no. 41, pp. 79-93, 1973.

[57] J. D. Figueroa, T. Fout, S. Plasynski, H. Mcllvried, and R. D. Srivastava, "Advances in $\mathrm{CO}_{2}$ capture technology-The U.S. Department of Energy's Carbon Sequestration Program," International Journal of Greenhouse Gas Control, vol. 2, no. 1, pp. 9-20, 2008.

[58] M. Smiglak, W. M. Reichert, J. D. Holbrey et al., "Combustible ionic liquids by design: is laboratory safety another ionic liquid myth?" Chemical Communications, no. 24, pp. 2554-2556, 2006.

[59] M. J. Earle, J. M. S. S. Esperança, M. A. Gilea et al., "The distillation and volatility of ionic liquids," Nature, vol. 439, no. 7078, pp. 831-834, 2006.

[60] D. Camper, J. Bara, C. Koval, and R. Noble, "Bulk-fluid solubility and membrane feasibility of Rmim-based room-temperature ionic liquids," Industrial and Engineering Chemistry Research, vol. 45 , no. 18 , pp. 6279-6283, 2006.
[61] T. K. Carlisle, J. E. Bara, C. J. Gabriel, R. D. Noble, and D. L. Gin, "Interpretation of $\mathrm{CO}_{2}$ solubility and selectivity in nitrilefunctionalized room-temperature ionic liquids using a group contribution approach," Industrial and Engineering Chemistry Research, vol. 47, no. 18, pp. 7005-7012, 2008.

[62] A. Finotello, J. E. Bara, D. Camper, and R. D. Noble, "Roomtemperature ionic liquids: temperature dependence of gas solubility selectivity," Industrial and Engineering Chemistry Research, vol. 47, no. 10, pp. 3453-3459, 2008.

[63] Y. I. Park, B. S. Kim, Y. H. Byun, S. H. Lee, E. W. Lee, and J. M. Lee, "Preparation of supported ionic liquid membranes (SILMs) for the removal of acidic gases from crude natural gas," Desalination, vol. 236, no. 1-3, pp. 342-348, 2009.

[64] D. Camper, C. Becker, C. Koval, and R. Noble, "Low pressure hydrocarbon solubility in room temperature ionic liquids containing imidazolium rings interpreted using regular solution theory," Industrial and Engineering Chemistry Research, vol. 44, no. 6, pp. 1928-1933, 2005.

[65] P. Scovazzo, J. Kieft, D. A. Finan, C. Koval, D. DuBois, and R. Noble, "Gas separations using non-hexafluorophosphate [PF6]anion supported ionic liquid membranes," Journal of Membrane Science, vol. 238, no. 1-2, pp. 57-63, 2004.

[66] H. Ohno, M. Yoshizawa, and W. Ogihara, "Development of new class of ion conductive polymers based on ionic liquids," Electrochimica Acta, vol. 50, no. 2-3, pp. 255-261, 2004.

[67] X. Hu, J. Tang, A. Blasig, Y. Shen, and M. Radosz, " $\mathrm{CO}_{2}$ permeability, diffusivity and solubility in polyethylene glycolgrafted polyionic membranes and their $\mathrm{CO}_{2}$ selectivity relative to methane and nitrogen," Journal of Membrane Science, vol. 281, no. 1-2, pp. 130-138, 2006.

[68] J. E. Bara, S. Lessmann, C. J. Gabriel, E. S. Hatakeyama, R. D. Noble, and D. L. Gin, "Synthesis and performance of polymerizable room-temperature ionic liquids as gas separation membranes," Industrial and Engineering Chemistry Research, vol. 46, no. 16, pp. 5397-5404, 2007.

[69] J. Tang, W. Sun, H. Tang, M. Radosz, and Y. Shen, "Enhanced $\mathrm{CO}_{2}$ absorption of poly(ionic liquid)s," Macromolecules, vol. 38, no. 6, pp. 2037-2039, 2005.

[70] J. E. Bara, C. J. Gabriel, S. Lessmann et al., "Enhanced $\mathrm{CO}_{2}$ separation selectivity in oligo(ethylene glycol) functionalized room-temperature ionic liquids," Industrial and Engineering Chemistry Research, vol. 46, no. 16, pp. 5380-5386, 2007.

[71] Y. C. Hudiono, T. K. Carlisle, J. E. Bara, Y. Zhang, D. L. Gin, and R. D. Noble, "A three-component mixed-matrix membrane with enhanced $\mathrm{CO}_{2}$ separation properties based on zeolites and ionic liquid materials," Journal of Membrane Science, vol. 350, no. 1-2, pp. 117-123, 2010.

[72] J. E. Bara, D. L. Gin, and R. D. Noble, "Effect of anion on gas separation performance of polymer-room-temperature ionic liquid composite membranes," Industrial and Engineering Chemistry Research, vol. 47, no. 24, pp. 9919-9924, 2008.

[73] Y. C. Hudiono, T. K. Carlisle, A. L. LaFrate, D. L. Gin, and R. D. Noble, "Novel mixed matrix membranes based on polymerizable room-temperature ionic liquids and SAPO-34 particles to improve $\mathrm{CO}_{2}$ separation," Journal of Membrane Science, vol. 370, no. 1-2, pp. 141-148, 2011.

[74] C. A. Oral, R. D. Noble, and S. B. Tantekin-Ersolmaz, “Ternary mixed-matrix membranes containing room temperature ionic liquids," in Proceedings of the North American Membrane Society Conference (NAMS '11), 2011. 

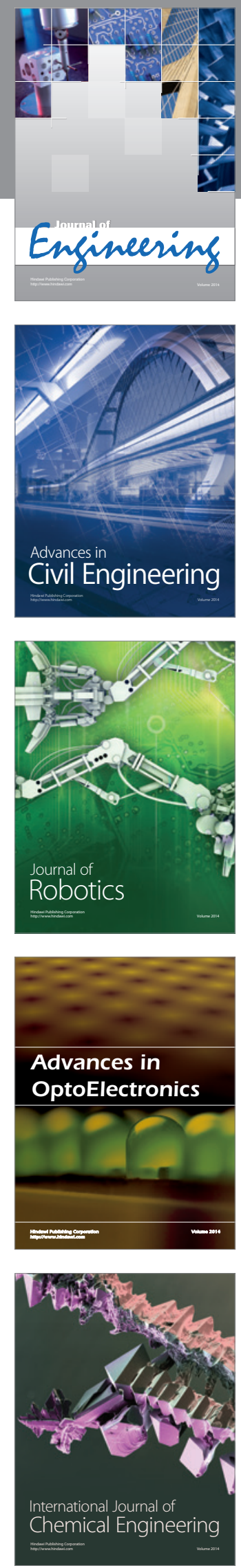

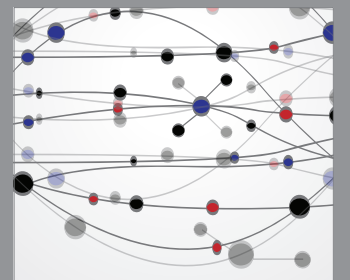

The Scientific World Journal
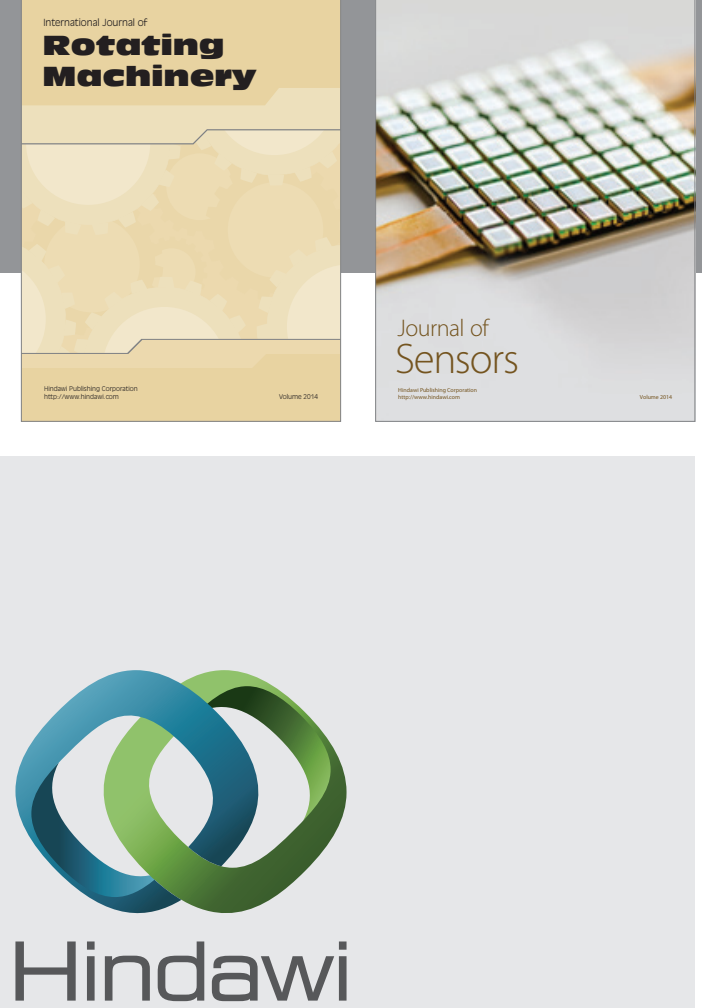

Submit your manuscripts at http://www.hindawi.com
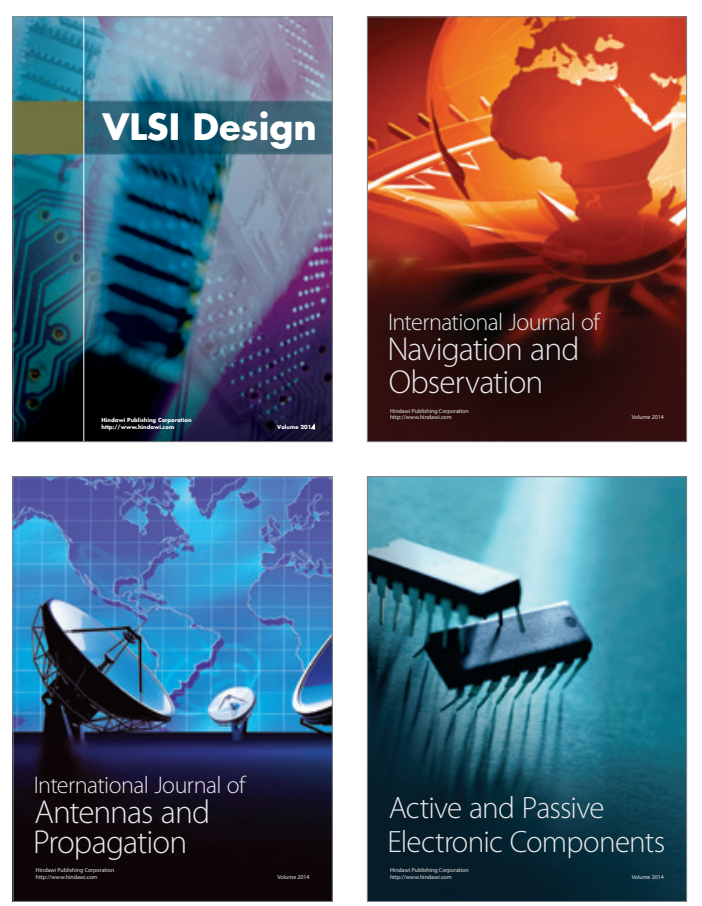
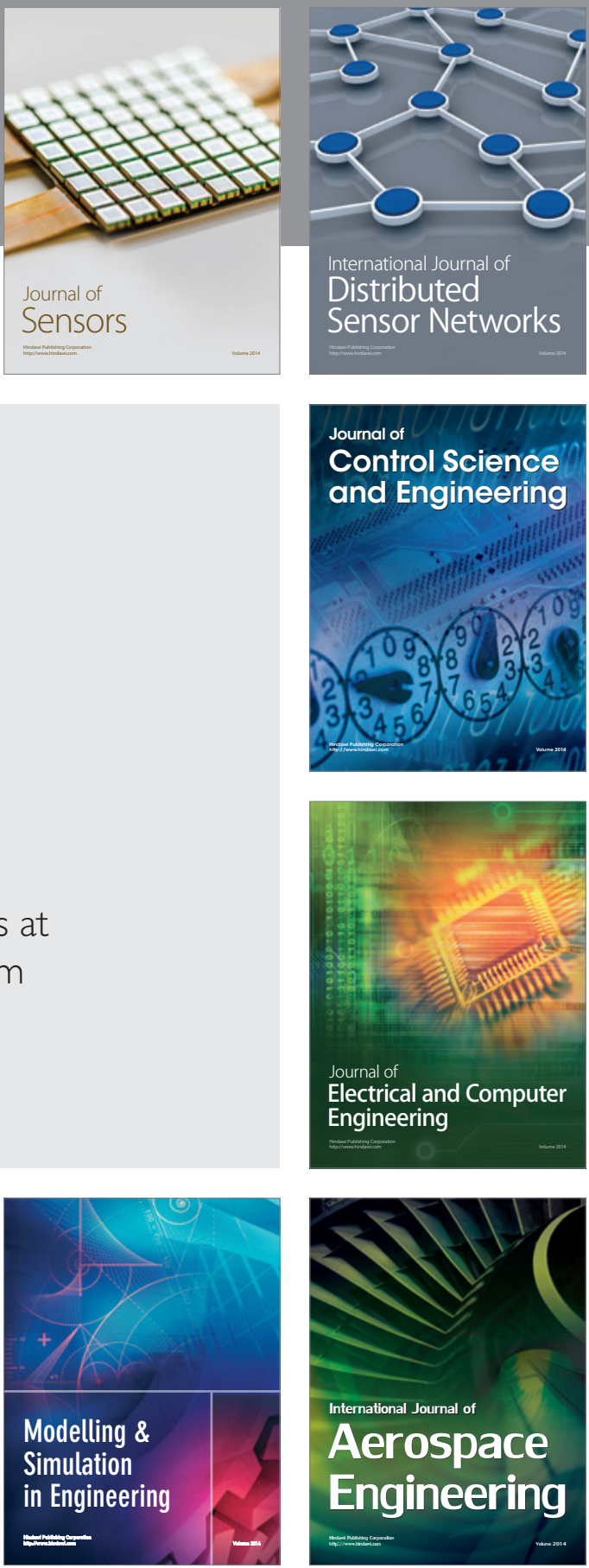

Journal of

Control Science

and Engineering
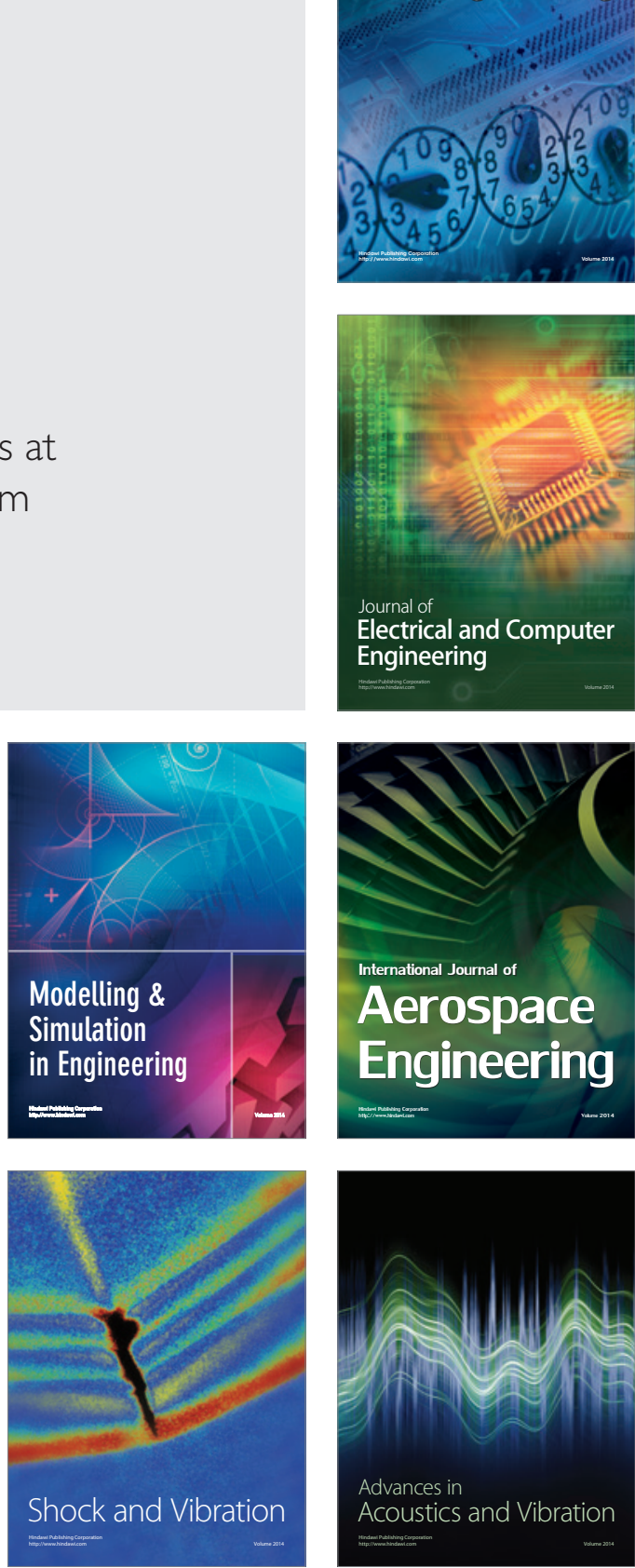